\title{
TRUSTWORTHY PREDICTION OF BURSTING STRENGTH OF DUCTILE IRON PIPES BASED ON FITNET FSS CRITERION
}

\author{
A. Chennakesava Reddy \\ Professor, Department of Mechanical Engineering, JNT University, Hyderabad-500 085, India \\ chennakesava@jntuh.ac.in
}

\begin{abstract}
The objective of the present work was to predict the bursting pressure of ductile iron pipes using Fitnet FSS criterion. The failure of the pipes was evaluated based on the Tresca and von Mises criteria. The significance of crack dimensions was recognized using Taguchi techniques. The highly influencing crack dimensions were pipe thickness and crack depth. The results obtained by the Fitnet FSS criterion have been in line with those of experimentation.
\end{abstract}

Keywords: Ductile iron, crack depth, crack length, bursting pressure, Fitnet FSS, Tresca criterion, von Mises criterion.

\section{INTRODUCTION}

Very often water pipelines get damaged either due to corrosion or owing to high pressure flow. With respect to integrity and safety of a pipe system, it is necessary to know the maximum pressure load it can withstand without leakage and catastrophic fracture. One of the most serious problems of pipes is corrosion. The gas pipes burst due to internal or external corrosion cracks (figure 1).
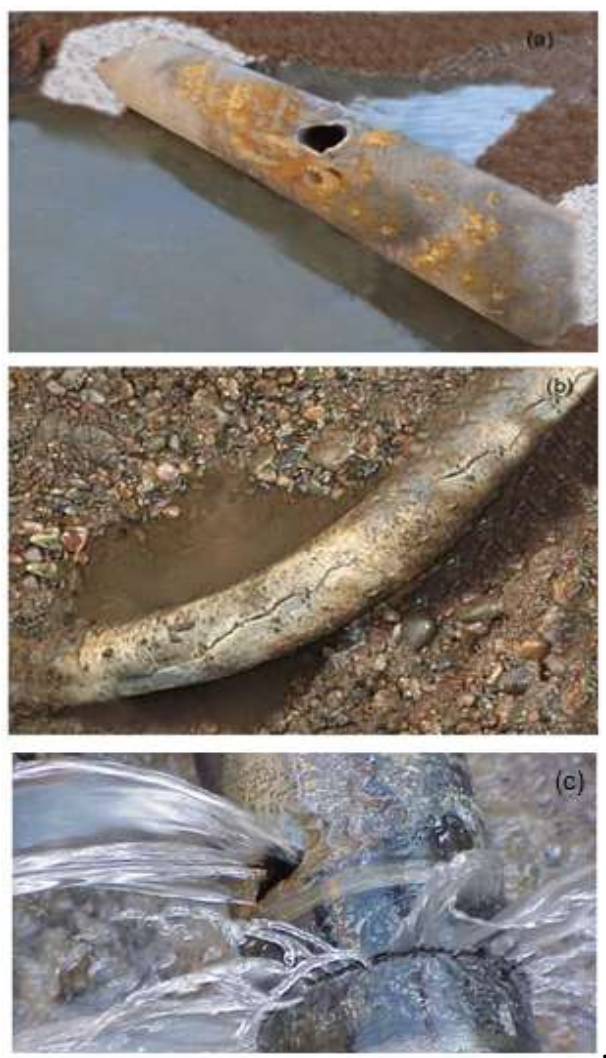

Figure 1: Damages in water pipelines due to corrosion flaws.
Very old pipelines get corroded resulting in leakage of water or bursting of pipe. The consequential problem is that the drinking water goes waste. In such situation it is very difficult to supply drinking water. Figure 2 gives scenarios of waiting for and struggling for drinking water.
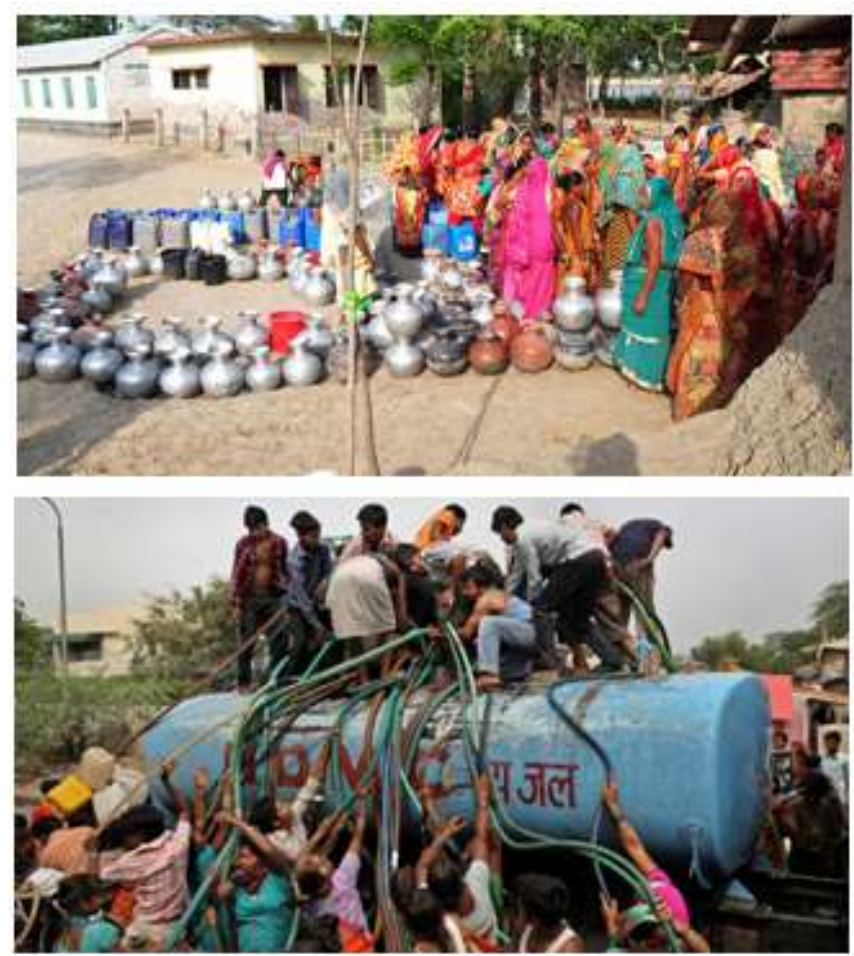

Figure 2: Scenarios of waiting for and struggling for drinking water.

In sewage system, cracked and damaged pipes can cause wastewater seepage, leading to contamination of ground water apart from other host of problems. These problems often give rise to related health and environmental impacts and are needed to be corrected at an early age. Sewerage and 
water infrastructure and other utility services represent a significant investment on the part of most municipalities. For well over 100 years, the distribution networks for utility services have been located underground in pipes or ducts that are laid, repaired or replaced by trenching from surface. Safe drinking water and sanitation are critical determinants of health. Because of scarcity of drinking water, people are collecting and drinking contaminated water (figure 3 ) irrespective of age and maturity because of unavoidable situation. The pipeline damages also throw challenges safety in the transportation systems. In cities and urban areas, these pipeline systems are located underneath the roads. Figure 4 shows the road damage on account of pipeline burst.

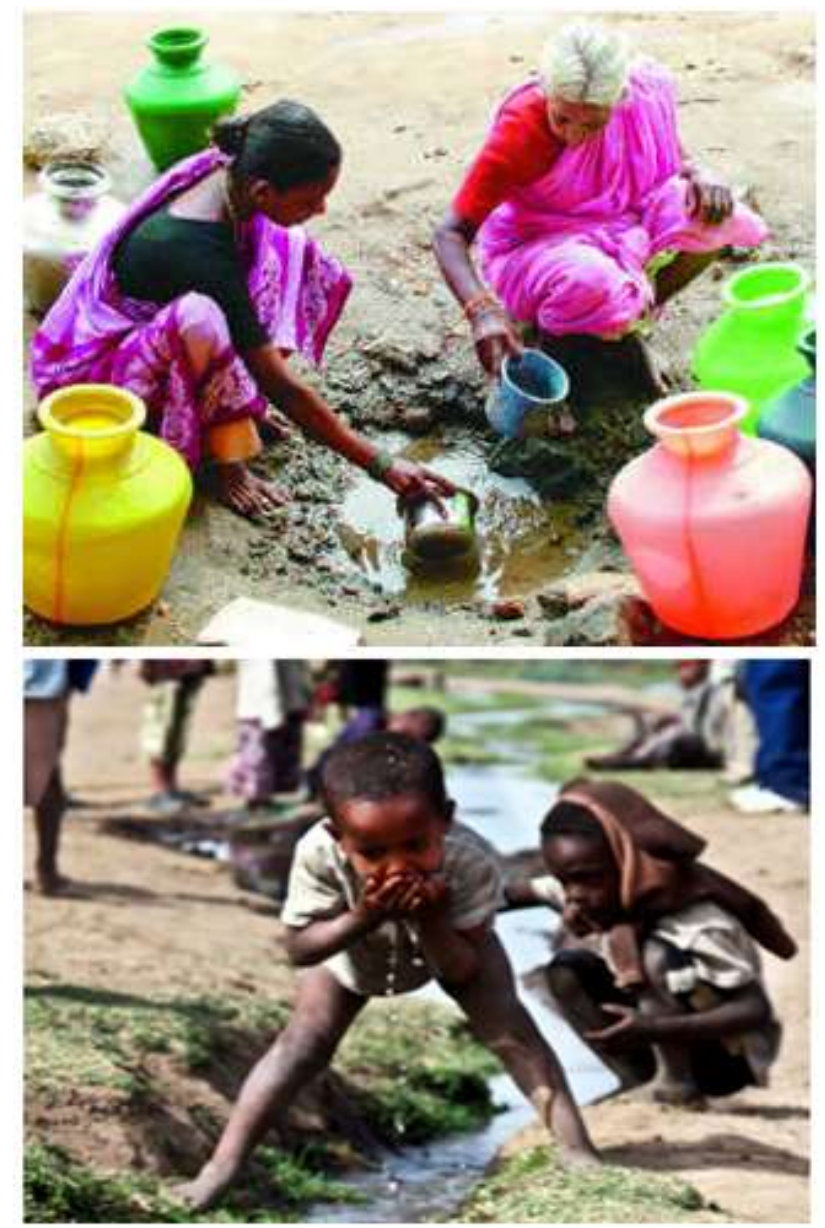

Figure 3: Situations of collecting or drinking the contaminated water.

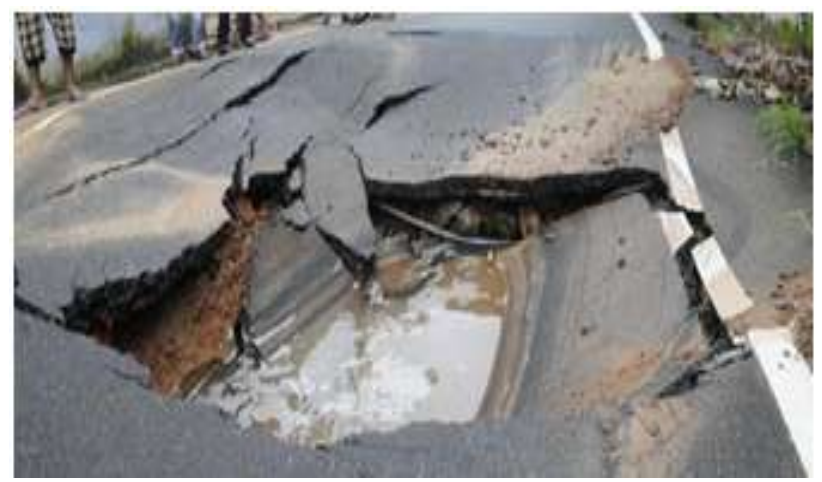

Figure 4: Damage of road due to pipeline burst.
Although literature on fracture mechanics of the pipelines is abundant, there is no assessment method that is precise and largely acknowledged. Most popular failure pressure methods for pressurized pipes with active corrosion defects are ASME B31G [1], DNV-RP-F101 [2], SHELL-92 [3], RSTRENG [4]. These methods were applied for the assessment of 302, 304, 305 and 316 stainless pipes [5-11].

The choice of the material for a water line depends upon the characteristic of the conveyed fluid, of the soil where the pipe is supposed to be laid, the working conditions affecting the pipes (such as external loads, seismicity, working pressure, transient conditions) and local conditions that can be encountered in impervious zones or crossing roads, densely inhabited areas, waterways etc.

The present work was motivated to optimize safety criteria for pressurized ductile iron tension grade 60-40-18 (DI-1), ductile iron tension grade 65-45-12 (DI-2) and ductile iron tension grade 80-55-06 (DI-3) pipes having $300 \mathrm{~mm}$ diameter. The present study was to predict the bursting pressure of the pipes with different crack dimensions using Fitnet FSS criterion. The bursting pressure was optimized using Taguchi techniques. The results were also cross-checked with those computed from ASME B31G, DNV-RP-F101, SHELL-92, and RSTRENG.

\section{MATERIAL AND METHODS}

The material of pipes was ductile iron. The chosen control parameters are summarized in table 1. The control factors were assigned to the various columns of orthogonal array (OA), L9 is given in table 2. The dimensions of notch are given in figure 5 .

Table 1: Control factors and their levels

\begin{tabular}{|l|c|c|c|c|}
\hline Factor & Symbol & Level-1 & Level-2 & Level-3 \\
\hline Thickness, mm & A & 3 & 4 & 5 \\
\hline Length of crack, mm & B & 150 & 200 & 250 \\
\hline Depth of crack & C & $30 \% \mathrm{t}$ & $40 \% \mathrm{t}$ & $50 \% \mathrm{t}$ \\
\hline Grade of ductile iron & D & DI-1 & DI-2 & DI-3 \\
\hline
\end{tabular}

where $t$ is pipe thickness

Table 2: Orthogonal Array (L9) and control factors

\begin{tabular}{|l|l|l|l|l|}
\hline Treat No. & A & B & C & D \\
\hline 1 & 1 & 1 & 1 & 1 \\
\hline 2 & 1 & 2 & 2 & 2 \\
\hline 3 & 1 & 3 & 3 & 3 \\
\hline 4 & 2 & 1 & 2 & 3 \\
\hline 5 & 2 & 2 & 3 & 1 \\
\hline 6 & 2 & 3 & 1 & 2 \\
\hline 7 & 3 & 1 & 3 & 2 \\
\hline 8 & 3 & 2 & 1 & 3 \\
\hline 9 & 3 & 3 & 2 & 1 \\
\hline
\end{tabular}




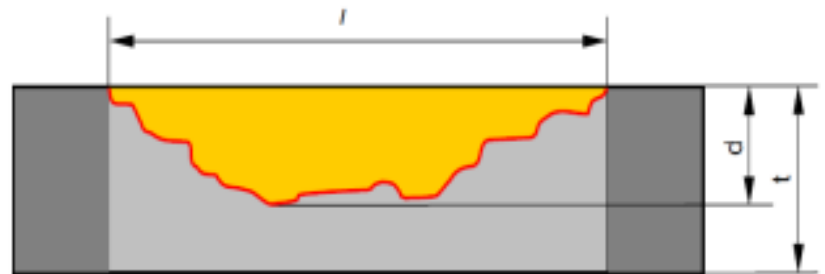

Figure 5: The Crack dimensions.

Using Fitnet FSS criterion [9], the bursting pressure can be estimated as follows:

$$
\begin{aligned}
& \mathrm{P}_{\mathrm{b}}=\frac{2 \operatorname{tUTS}(0.5)^{65 / \mathrm{YS}}}{\mathrm{D}}\left[\frac{1-\frac{\mathrm{d}}{\mathrm{t}}}{1-\frac{\mathrm{d}}{\mathrm{t}} \mathrm{M}_{\mathrm{f}}}\right] \\
& \mathrm{M}_{\mathrm{f}}=\sqrt{1+0.8 \frac{\mathrm{L}^{2}}{\mathrm{Dt}}}
\end{aligned}
$$

where, D and t are, respectively, the nominal outside diameter and thickness of the pipe. L and d are, respectively, crack length and crack depth. UTS and YS are, respectively, the ultimate tensile strength and yield strength.

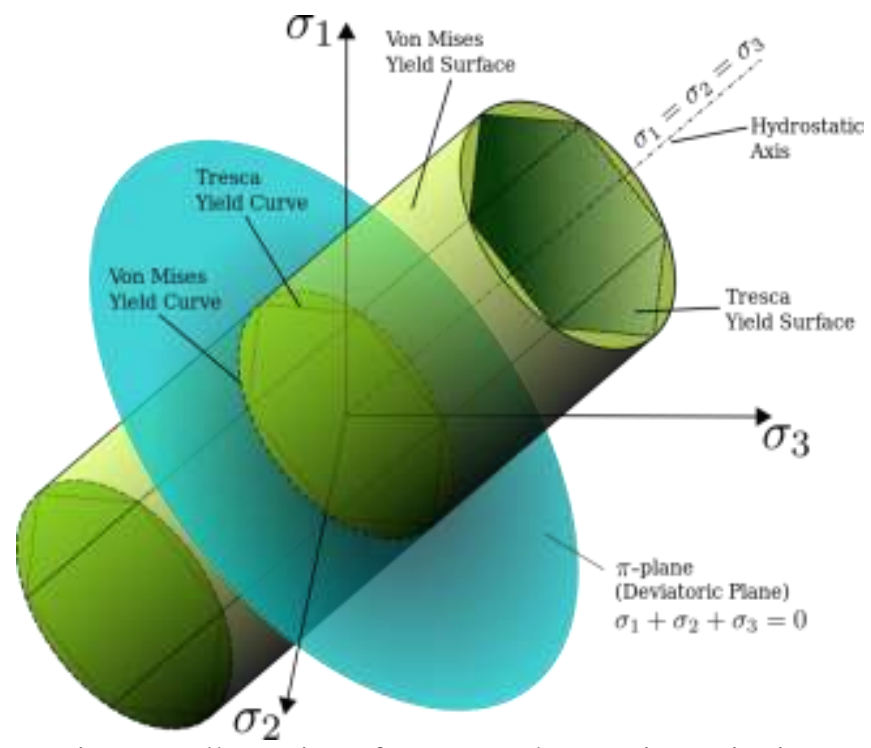

Figure 6: Illustration of Tresca and von Mises criteria.

For Fitnet FSS criterion, the Tresca criterion is the first classical yield criterion in the strength theory for isotropic ductile materials, often referred to as the maximum shear stress criterion. In principal stress space $\left(\sigma_{1}, \sigma_{2}, \sigma_{3}\right)$, the Tresca criterion can be expressed as

$\tau_{\max }=\max \left(\frac{\left|\sigma_{1}-\sigma_{2}\right|}{2}, \frac{\left|\sigma_{2}-\sigma_{3}\right|}{2}, \frac{\left|\sigma_{1}-\sigma_{3}\right|}{2}\right)=\frac{\sigma_{\mathrm{YS}}}{2}$

where $\tau \max$ is the maximum shear stress and $\sigma_{\mathrm{uts}}$ is the ultimate tensile strength in tension.

For Fitnet FSS criterion, the von Mises criterion is the second classical yield criterion in strength theory, often referred to as the octahedral shear stress criterion. It can be expressed by the principal stresses in the form:
$\tau_{\mathrm{vm}}=\sqrt{\frac{1}{6}\left[\left(\sigma_{1}-\sigma_{2}\right)^{2}+\left(\sigma_{2}-\sigma_{3}\right)^{2}+\left(\sigma_{3}-\sigma_{1}\right)^{2}\right]}=\frac{\sigma_{\mathrm{YS}}}{\sqrt{3}}$

where $\tau_{\mathrm{vm}}$ is the von Mises effective shear stress.

The von Mises yield surfaces in principal stress coordinates circumscribes a cylinder with radius $\sqrt{2 / 3 \sigma}$ around the hydrostatic axis. Also shown is Tresca's hexagonal yield surface (figure 6). Intersection of the von Mises yield criterion with the $\sigma_{1}, \sigma_{2}$ plane, where $\sigma_{3}=0$.

\section{RESULTS AND DISCUSSION}

The bursting pressures computed from PCORRC, ASME B31G, DNV-RP-F101, SHELL-92, RSTRENG and Fitnet FSS criteria are given in figure 7 . It is observed that the bursting pressures obtained through Fitnet FSS criterion form lower bound values whereas the bursting pressures attained through RSTRENG criterion form upper bound values. The pressure values computed using SHELL-92, DNV-RP F101 and PCORRC criteria are within these two limits. The results obtained using Fitnet FSS criterion were nearly equal to ASME B31G criterion. Therefore, the bursting pressures obtained through Fitnet FSS criterion are highly acceptable.

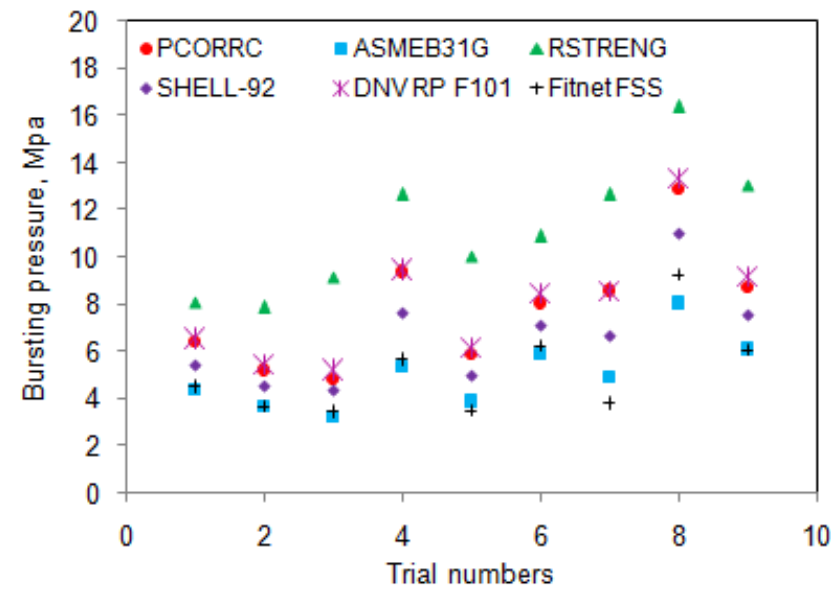

Figure 7: Bursting pressures computed from different methods.

\subsection{Influence of Crack Dimensions and Tube Ma-}

\section{terial on Bursting Strength}

Table 3 gives the ANOVA (analysis of variation) summary of bursting pressure. Even if all the process parameters could satisfy the Fisher's test at $90 \%$ confidence level, pipe thickness, crack depth and grade of ductile iron had major role in the total variation of bursting pressure. The pipe thickness (A), crack depth (C) and grade of ductile iron (D) had given, respectively, $31.86 \%, 49.15 \%$ and $15.28 \%$ in the total variation of the bursting pressure. The crack length (B) was insignificant.

Figure 8 shows the dependence of bursting pressure on the pie thickness. As the pipe thickness increased the pressure required to burst the pipe would also increase. If the crack depth increased, the pipe could fail even at low bursting pressure (figure 9). The required bursting pressure was high 
for the ductile tension grade 80-55-06 as compared to the other two grades (ductile tension grades $65-45-12$ and 60.40-18). The ductile iron tension grade 65-45-12 failed at low bursting pressure.

Table 3: ANOVA summary of the bursting pressure

\begin{tabular}{|c|c|c|c|c|c|c|c|c|}
\hline Source & Sum 1 & Sum 2 & Sum 3 & SS & v & V & F & P \\
\hline A & 11.64 & 15.30 & 19.12 & 9.34 & 1 & 9.34 & 7834.79 & 31.86 \\
\hline B & 13.94 & 16.41 & 15.71 & 1.08 & 1 & 1.08 & 905.95 & 3.68 \\
\hline C & 19.98 & 15.40 & 10.68 & 14.41 & 1 & 14.41 & 12087.73 & 49.15 \\
\hline D & 14.05 & 62.29 & 46.06 & 4.48 & 1 & 4.48 & 3758.02 & 15.28 \\
\hline e & & & & 0.004769 & 4 & 0.001192 & 1.00 & 0.03 \\
\hline T & 59.61 & 109.40 & 91.57 & 29.31477 & 8 & & & 100 \\
\hline
\end{tabular}

Note: SS is the sum of square, $\mathrm{v}$ is the degrees of freedom, $\mathrm{V}$ is the variance, $\mathrm{F}$ is the Fisher's ratio, $\mathrm{P}$ is the percentage of contribution and $\mathrm{T}$ is the sum squares due to total variation.

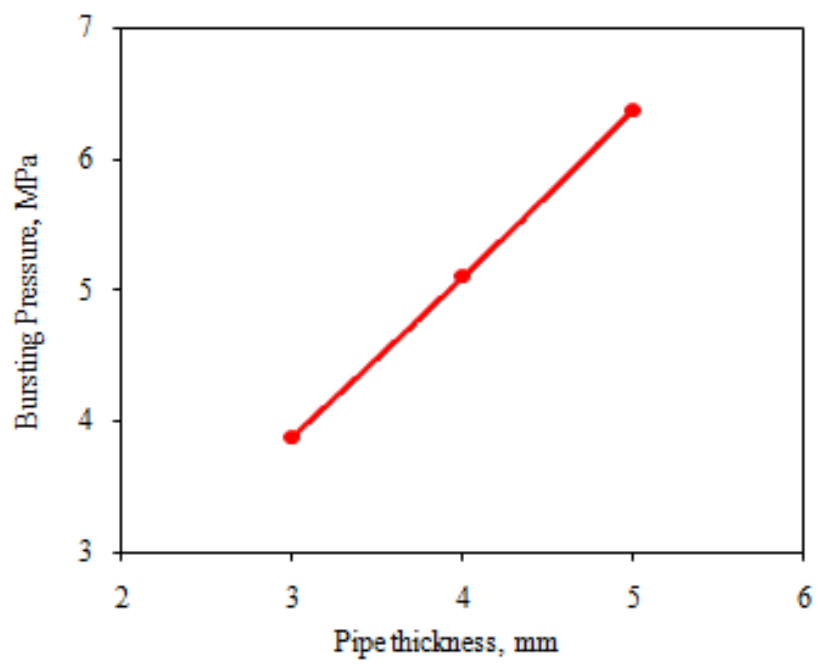

Figure 8: Effect of pipe thickness on bursting pressure.

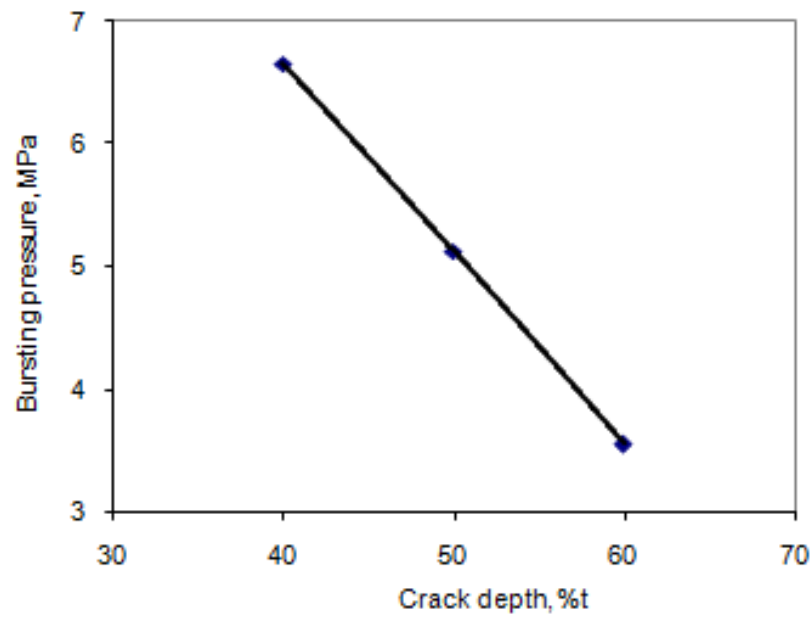

Figure 9: Effect of crack depth on bursting pressure.

\subsection{Failure Criteria}

Table 4 and 5 give the ANOVA (analysis of variation) summary of Tresca criterion and von Mises criterion respectively. Even though all the process parameters could assure the Fisher's test at $90 \%$ confidence level, only crack depth and grade of ductile iron had foremost roles in the total variation of Tresca and von Mises criteria. The crack depth (C) contributed nearly $81.41 \%$ of the total variation in the Tresca and von Mises criteria. The grade of ductile (D) put in $16.93 \%$ of the total variation in the Tresca and von Mises criteria. The pipe thickness and the crack length were insignificant in the variation of Tresca and von Mises criteria.

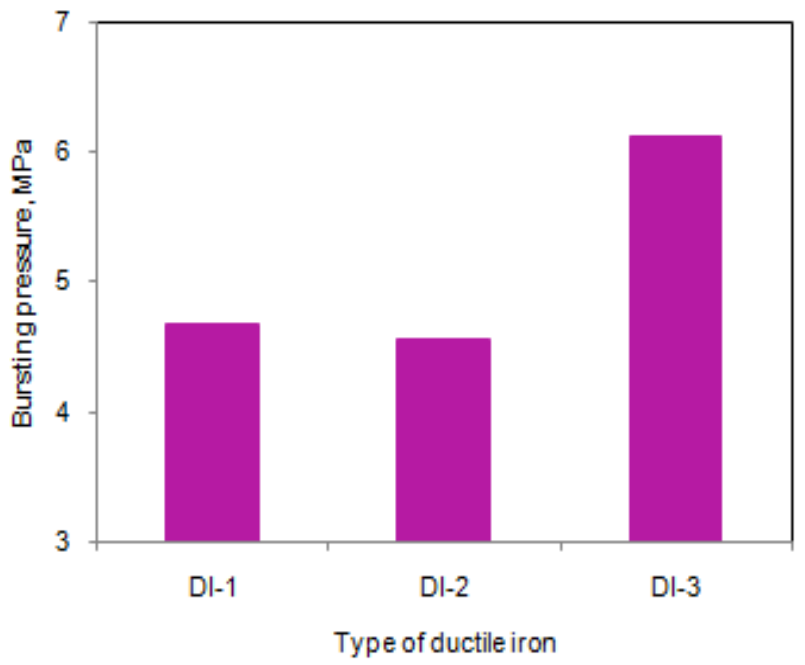

Figure 10: Effect of ductile iron grade on bursting pressure.

Table 4: ANOVA summary of the Tresca criterion

\begin{tabular}{|c|c|c|c|c|c|c|c|c|}
\hline Source & Sum 1 & Sum 2 & Sum 3 & SS & v & V & F & P \\
\hline A & 288.03 & 283.06 & 282.05 & 6.83 & 1 & 6.83 & 1264.75 & 0.13 \\
\hline B & 271.95 & 291.87 & 289.32 & 78.29 & 1 & 78.29 & 14497.35 & 1.53 \\
\hline C & 363.11 & 285.19 & 204.84 & 4175.29 & 1 & 4175.29 & 773159.48 & 81.41 \\
\hline D & 265.39 & 22836.42 & 853.14 & 868.59 & 1 & 868.59 & 160841.18 & 16.93 \\
\hline e & & & & 0.021601 & 4 & 0.005400 & 1.00 & 0 \\
\hline T & 1188.5 & 23696.54 & 1629.36 & 5128.978 & 8 & & & 100 \\
\hline
\end{tabular}

Table 5: ANOVA summary of the von Mises criterion

\begin{tabular}{|c|c|c|c|c|c|c|c|c|}
\hline Source & Sum 1 & Sum 2 & Sum 3 & SS & v & V & F & P \\
\hline A & 498.88 & 490.28 & 488.53 & 20.47 & 1 & 20.47 & 17045.72 & 0.13 \\
\hline B & 471.04 & 505.53 & 501.13 & 234.86 & 1 & 234.86 & 195571.95 & 1.53 \\
\hline C & 628.93 & 493.96 & 354.80 & 12525.85 & 1 & 12525.85 & 10430490 & 81.41 \\
\hline D & 459.68 & 68509.25 & 1477.69 & 2605.75 & 1 & 2605.75 & 2169852.7 & 16.93 \\
\hline e & & & & 0.004803 & 4 & 0.001200 & 1.00 & 0 \\
\hline T & 2058.5 & 69999.02 & 2822.14 & 15386.92 & 8 & & & 100 \\
\hline
\end{tabular}


As the crack depth increased the level of failure shear stress decreased (figure 11). The level of maximum shear stress was low for ductile iron tension grade 65-45-12 and it was high for ductile iron tension grade 80-55-06 (figure 12). As observed from figure 13, all the pipes were safe under Tresca failure criterion. From figure 14 it is observed that the pipes numbered 6 and 8 did not satisfy the von Mises failure criterion. The pipe 1 was at the threshold of failure. The remaining pipes were safe under von Mises failure criterion.

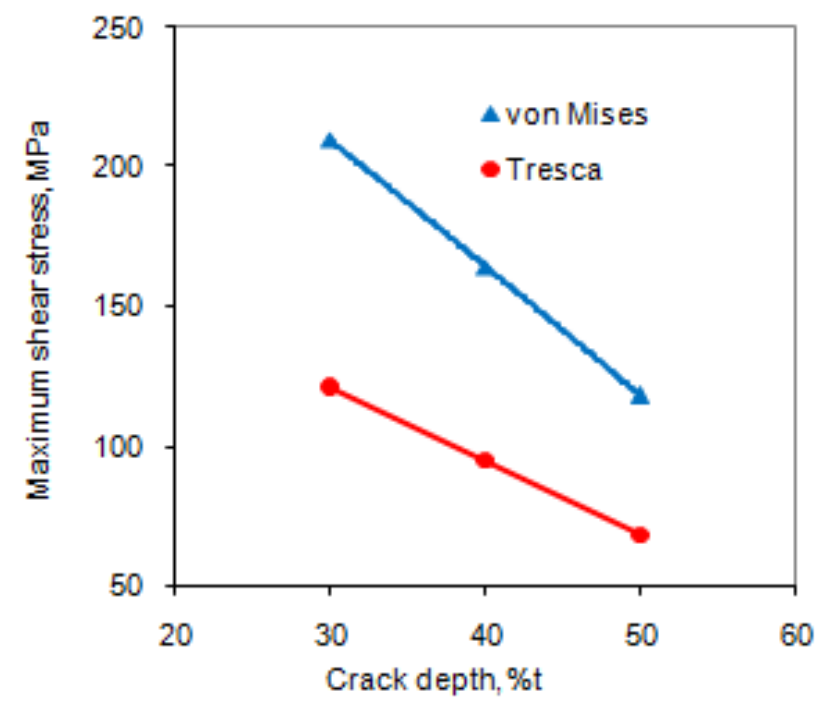

Figure 11: Effect of crack depth on failure criteria.

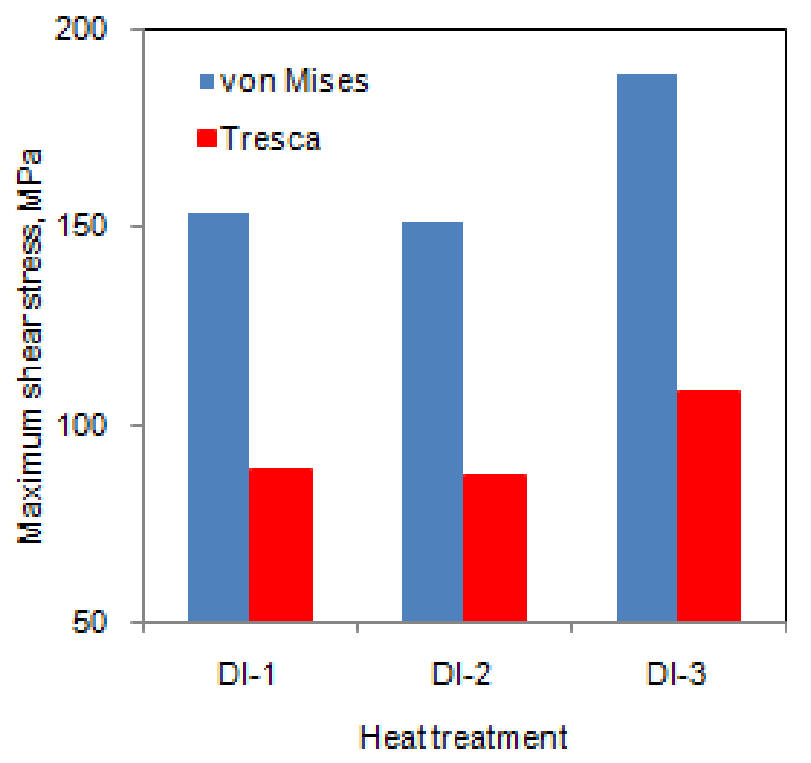

Figure 12: Effect of grade of ductile iron on failure criteria.

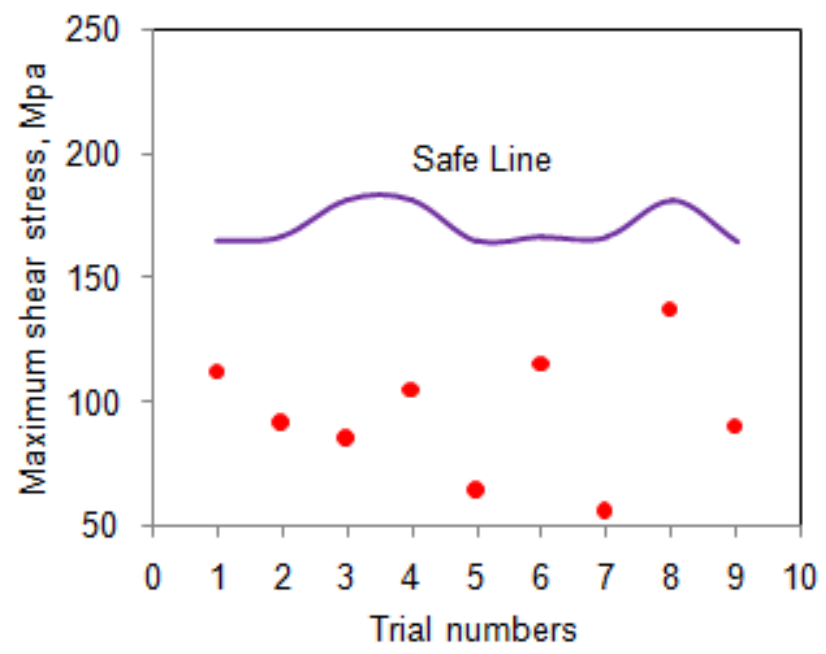

Figure 13: Tresca failure criterion of all pipes.

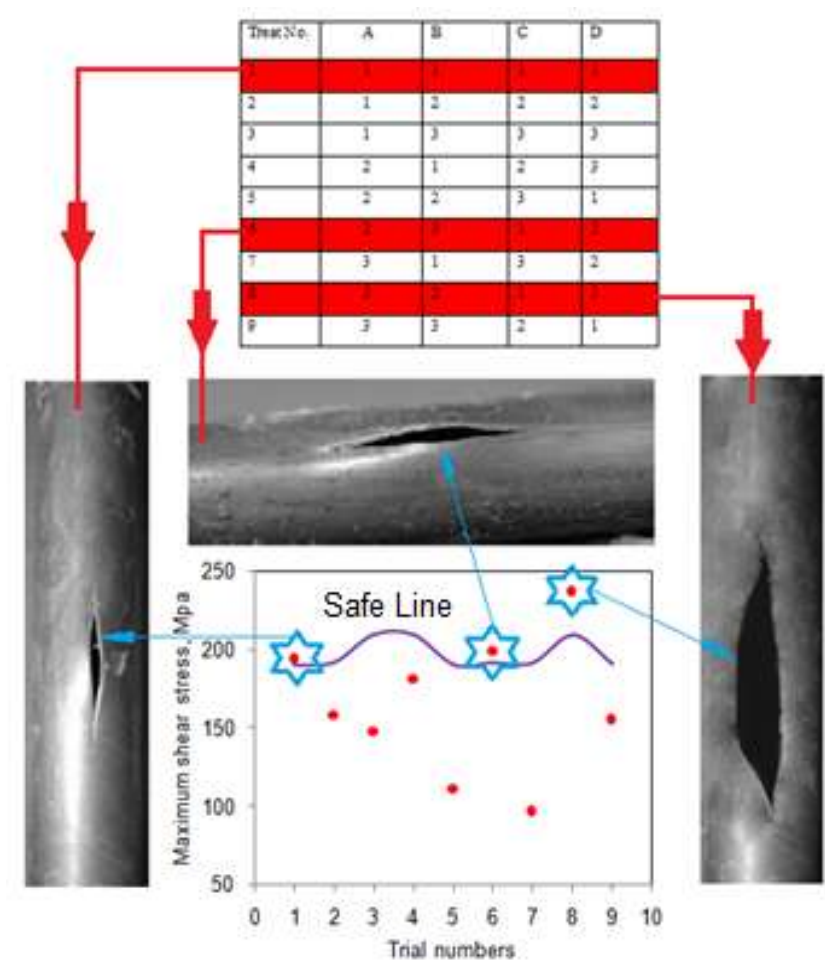

Figure 14: von Mises failure criterion of all pipes.

\section{CONCLUSIONS}

The bursting pressure is highly dependent on the pipe thickness, crack depth and grade of ductile iron. The bursting pressure increases with the increase of pipe thickness. Also, the bursting pressure decreases with the increase of crack depth. The von Mises criterion is very near the failure pattern of the pipes. The Fitnet FSS criterion could predict the bursting pressure of the ductile iron steel pipes accurately harmonizing the experimental results.

\section{REFERENCES}

[1] American National Standards Institute (ANSI) / American Society of Mechanical Engineers (ASME): Manual for determining the remaining strength of corroded pipelines, ASME B31G, 1991. 
[2] Anon, DNV-RP-F101, Corroded Pipelines, Det Norske Veritas, 1999.

[3] D. Ritchie and S. Last, Burst Criteria of Corroded Pipelines - Defect Acceptance Criteria, Paper 32, Proceedings of the EPRG/PRC 10th Biennial Joint Technical Meeting on Line Pipe Research, Cambridge, UK, 18-21 April 1995, pp. 32-1 - 32-11.

[4] J. F. Kiefner and P. H. Vieth, A Modified Criterion for Evaluating the Strength of Corroded Pipe, Final Report for Project PR 3-805 to the Pipeline Supervisory Committee of the American Gas Association, Battelle, Ohio, 1989.

[5] A. C. Reddy, Prediction of bursting pressure of thin walled 316 stainless steel pipes based on ASME B31G criterion, National Conference on Advances in Design Approaches and Production Technologies (ADAPT2005), Hyderabad, 22-23rd August 2005, pp. 225-228.

[6] A. C. Reddy, Estimation of bursting pressure of thin walled 304 stainless steel pipes based on DNV RP F101criterion, National Conference on Advances in Design Approaches and Production Technologies (ADAPT-2005), Hyderabad, 22-23rd August 2005, pp. 229-231.

[7] A. C. Reddy, Reliability assessment of corrosion cracks in cold rolled 302 stainless steel pipes based on SHELL-92 criterion, National Conference on Advances in Design Approaches and Production Technologies (ADAPT-2005), Hyderabad, 22-23rd August 2005, pp. 232-234.

[8] A. C. Reddy, Trustworthiness judgment of corrosion cracks in cold rolled 305 stainless steel pipes based on RSTRENG criterion, National Conference on Advances in Design Approaches and Production Technologies (ADAPT-2005), Hyderabad, 22-23rd August 2005, pp. 235-237.

[9] A. C. Reddy, Consistency prediction of bursting strength of 317 stainless steel pipes based on PCORSS (Batelle) criterion, National Conference on Excellence in Manufacturing and Service Organizations: The Six Sigma Way, Hyderabad, 26-27th August 2010, pp. 105108.

[10] A. Chennakesava Reddy, Reliable forecasting of remaining strength of petroleum pipelines based on LG18 criterion, National Conference on Excellence in Manufacturing and Service Organizations: The Six Sigma Way, Hyderabad, 26-27 August 2010, 109-111.

[11]A. Chennakesava Reddy, Decent prophecy of bursting strength of natural gas pipelines based on modified ASME B31G criterion, National Conference on Excellence in Manufacturing and Service Organizations: The Six Sigma Way, Hyderabad, 26-27 August 2010, 112115.

[12] GTC1 - 2001 - 43049, FITNET, European Fitness for Service Network. 